\title{
CULTURA E AS MANIFESTAÇÕES ARTÍSTICAS COMO UM ATRATIVO TURÍSTICO EM NATAL - RN: UM ESTUDO NA PERCEPÇÃO DOS STAKEHOLDERS.
}

\author{
M.sc. Richard Medeiros de Araújo \\ Universidade Federal do Rio Grande do Norte-e-mail: richardmaraujo@uol.com.br \\ Amanda F. G. Posenatto \\ Faculdade de Ciências, Cultura e Extensão do RN - e-mail: \\ amanda_posenatto@hotmail.com \\ Ana Cléia Nascimento \\ Faculdade de Ciências, Cultura e Extensão do RN - e-mail: cleia_p1 @hotmail.com
}

\begin{abstract}
RESUMO
Este artigo discute a necessidade de adoção de novas práticas e novos produtos turísticos na cidade do Natal. A pesquisa tem por objetivo central analisar as manifestações artísticas como potencial turístico a partir da percepção dos stakeholders (dentro do turismo eles são as pessoas envolvidas na atividade, tais como: empresários de hotéis e restaurantes, agentes de viagem, secretário de turismo, os turistas e diversos outros). A metodologia da pesquisa carcaterizou-se como exploratória, bibliográfica, de campo e qualitativa; foram aplicados formulários compostos de perguntas abertas e fechadas, bem como entrevistas, com os stakeholders, sujeitos desta pesquisa. Assim, foi possível concluir que Natal apresenta potencial para o desenvolvimento do turismo cultural, e que as manifestações artísticas são importantes ferramentas para isso; os turistas esperam por novos produtos turísticos, dentro desse segmento. Porém é necessário obter uma atenção maior dos stakeholders, ligados ao serviço da atividade turística, para desenvolver outras modalidades do turismo que não seja o de sol e mar. Dessa forma, será possível propagar a capital potiguar por outros atrativos, além dos naturais, bem como descentralizar a oferta turística no destino.
\end{abstract}

PALAVRAS-CHAVE: Natal. Stakeholders. Turismo Cultural

\section{CULTURAL AND ARTISTIC EVENTS AS AN ATTRACTIVE TOURIST IN NATAL - RN: A STUDY IN PERCEPTION OF STAKEHOLDERS}

\begin{abstract}
This article discuss the needs of adoption for new techniques and new touristic products in the city of Natal. The research is centrally focused on the analysis of artistic expressions as touristic potential from the perception of stakeholders (within the tourism they are the ones involved in the activities, such as: entrepreneurs of hotels and restaurants, travel agents, tourism secretary, tourists themselves, among others). The methodology of the research was characterized as exploratory, bibliographic, of field and qualitative; forms composed by open and closed questions have been applied, as well as interviews with the stakeholders, subjects of this research. Thus, it was possible to conclude that Natal has the potential to the development of cultural tourism, and that the artistic expression are important tools for this matter; tourists expect for new touristic products, within this segment. However, it is necessary to obtain greater attention from the stakeholders, linked
\end{abstract}


to the service of touristic activities, to develop other modalities of tourism beyond the sun and the sea. This way, it will be possible to propagate Natal for other attractions, besides its natural beauty, as well as decentralize the touristic offer in the place.

KEY-WORDS: City Natal. Stakeholders. Cultural Tourism 


\section{CULTURA E AS MANIFESTAÇÕES ARTÍSTICAS COMO UM ATRATIVO TURÍSTICO EM NATAL - RN: UM ESTUDO NA PERCEPÇÃO DOS STAKEHOLDERS.}

\section{INTRODUÇÃO}

A força do turismo no mundo, em razão de seu grande raio de atuação, tem sido objeto de estudo de pesquisadores de diversas áreas - principalmente entre as ciências econômicas. Conforme se observa na fala de Cooper et al. (2000), independentemente do grau de desenvolvimento em que um país se encontre, a atividade turística vai responder por grande parte do Produto Interno Bruto - PIB, uma vez que engloba uma série de produtos e serviços diferentes, mas complementares. Ainda segundo o autor, o turismo pode ser considerado importante elemento da economia de serviços por sua característica de crescimento contínuo e rápido, capaz de suportar as pressões da recessão econômica mundial, não apenas mantendo sua presença, mas em muitas áreas, continuando a crescer.

Durante as últimas décadas, muitas economias cresceram em seus setores de serviços, mesmo quando os setores mais tradicionais, agrícolas e manufatureiros, estiveram sujeitos à estagnação ou ao declínio. O turismo é uma indústria baseada em serviços, e como tal, foi parcialmente responsável pelo crescimento desse setor. Nos países em desenvolvimento, o setor de serviços é responsável por cerca de $40 \%$ do Produto Interno Bruto, enquanto nas economias desenvolvidas ou industrializadas ele é responsável por mais de 65\% do PIB (COOPER: 2001).

Voltando ao foco da pesquisa para o objeto em questão observa-se que a limitação da modalidade turística desenvolvida em toda a região nordeste do país - o turismo de Sol e Mar não vem atendendo de forma satisfatória a demanda turística, tanto nacional quanto internacional, conforme pode se verificar a partir de 2008, quando o número de visitantes começou a diminuir drasticamente por uma série de fatores: a crise financeira mundial, o aumento nos custos da viagem, a diminuição dos vôos charters e a falta de diversificação nos produtos turísticos oferecidos, além de problemas com a segurança pública, entre outros fatores, formaram num curto espaço de tempo um conjunto de características desfavoráveis ao desenvolvimento do turismo na capital do Rio Grande do Norte, principalmente entre os turistas estrangeiros.

A Tabela 01 pode melhor exemplificar o crescimento e o declínio no volume dos fluxos de turistas nacionais e estrangeiros em visita à cidade do Natal, no período de 1999 a 2007. Observa-se que em 2005, o fluxo de turistas estrangeiros na cidade chegou a $20 \%$ da demanda, sobretudo vindos de Portugal, Itália e Espanha, enquanto os outros 80\% corresponderam ao fluxo nacional. No entanto, a partir do ano seguinte os fluxos começaram a declinar chegando o estrangeiro a $16 \%$, ou seja, uma queda de $4 \%$. 


\begin{tabular}{|ccccccc|}
\hline \hline & \multicolumn{7}{c}{ Tabela 01 } & - Fluxos Turísticos no RN \\
\hline Anos & $\begin{array}{c}\text { Fluxo } \\
\text { Brasileiros }\end{array}$ & $\mathbf{\%}$ & $\begin{array}{c}\text { Fluxo } \\
\text { Estrangeiros }\end{array}$ & \% & Fluxo Total & \% \\
\hline $\mathbf{1 9 9 9}$ & 846.537 & 92,34 & 70.222 & 7,66 & 916.759 & 100 \\
$\mathbf{2 0 0 0}$ & 925.065 & 91,73 & 83.370 & 8,27 & 1.008 .435 & 100 \\
$\mathbf{2 0 0 1}$ & 985.095 & 90 & 104.015 & 10 & 1.089 .110 & 100 \\
$\mathbf{2 0 0 2}$ & 882.227 & 88 & 117.467 & 12 & 999.694 & 100 \\
$\mathbf{2 0 0 3}$ & 837.911 & 83 & 168.855 & 17 & 1.006 .766 & 100 \\
$\mathbf{2 0 0 4}$ & 975.296 & 81 & 226.915 & 19 & 1.202 .211 & 100 \\
$\mathbf{2 0 0 5}$ & 1.086 .016 & 80 & 269.664 & 20 & 1.355 .680 & 100 \\
$\mathbf{2 0 0 6}$ & 1.147 .221 & 84 & 226.012 & 16 & 1.373 .233 & 100 \\
\hline $\mathbf{2 0 0 7}$ & $\mathbf{9 7 5 . 2 9 6}$ & $\mathbf{8 1 , 1 3}$ & $\mathbf{2 2 6 . 9 1 5}$ & $\mathbf{1 8 , 8 7}$ & $\mathbf{1 . 2 0 2 . 2 1 1}$ & $\mathbf{1 0 0}$ \\
\hline
\end{tabular}

Fonte: Indicadores básicos, SETUR/RN, 1999-2007

É fato que toda a região nordeste esteja sofrendo com as variações desses fluxos, mas alguns estados como Pernambuco e Bahia estiveram antevendo essa situação e já começaram a fomentar ações no sentido de complementar e agregar valor aos atrativos de sol e mar atualmente oferecidos. Em Pernambuco, os pacotes turísticos vendem além das praias, opções de passeios às regiões como Caruaru, com seu tradicional São João ou o Auto da Paixão, em Nova Jerusalém - manifestações populares que vem ganhando força e atenção por parte do turista, que recebe um grande leque de opções no que diz respeito aos produtos turísticos que lhe são oferecidos. Não obstante, observa-se que Natal faz parte da situação descrita anteriormente.

Esse artigo busca fomentar algumas reflexões no sentido de colocar em pauta a possibilidade de diversificar a oferta turística da cidade, através dos atrativos culturais, com uma atenção específica nas manifestações artísticas. Tendo por finalidade, analisar essas manifestações como potencial turístico na percepção dos stakeholders ${ }^{l}$ que estrategicamente deveriam formar uma rede de relações sociais que culminasse com melhorias na gestão do turismo; identificando como têm sido as práticas adotadas pelo município na busca por novos produtos turísticos; debater a importância das manifestações artísticas na valorização cultural da cidade; discutir o turismo cultural como alternativa de negócio e elucidar a importância dos stakeholders dentro da atividade turística no destino Natal.

Assim, foi possível agregar material para futuros estudos mais aprofundados a respeito da cultura e do potencial artístico da cidade como objeto do turismo. Todo conteúdo aqui apresentado, também pode tornar-se importante ferramenta no que se refere ao estudo e análise da descentralização da oferta turística e da necessidade da busca por novos atrativos turísticos que possam vir a se tornar produtos consolidados na cidade. Cabe aqui destacar, na fala de Ruschmann (1997), as três categorias de elementos de interesse para o turismo:

- recursos turísticos: elementos com potencial para atrair fluxos de turistas; ainda não foram apropriados pela atividade turística;

- atrativos turísticos: reúnem os predicados necessários, mas não dispõem da infra-estrutura necessária nem justificam a viagem por si só embora a complementem;

\footnotetext{
1 Os stakeholders do turismo são as pessoas envolvidas no mercado turístico, tais como: empresários de hotéis e restaurantes, agentes de viagem, secretário de turismo, os turistas e diversos outros.
} 
- produto turístico: já recebe fluxos de turistas, possui infra-estrutura, acessibilidade e justifica por si só o deslocamento do viajante.

As manifestações artísticas objeto deste estudo, consistem no patrimônio imaterial da cidade e compõem um forte conjunto de atrativos em Natal, sendo pouco explorados atualmente.

No município existem diversas companhias teatrais, de dança e de música que, estão sempre em atividade, idealizando, desenvolvendo e realizando apresentações nas diversas esferas culturais.

As peças teatrais em Natal trabalham como forte expressão artística das raízes potiguares, envolvendo pessoas da própria localidade - sejam profissionais ou não, e destacam-se dentre os recursos turísticos culturais da cidade, sobretudo aquelas que falam da história local; que abordam em seu enredo o folclore do município e os temas religiosos, tais como: Auto do Natal, realizado todo final de ano, desde 1998, tratando do tema natalino; espetáculo Presente de Natal, que conta o nascimento de Jesus através de recursos artísticos que remetem à cultura local e a Paixão de Cristo. Os principais teatros de Natal são: o Teatro Alberto Maranhão e a Casa da Ribeira. O Alberto Maranhão localiza-se na Praça Augusto Severo, sem número, bairro da Ribeira na cidade de Natal; e pode ser considerado o maior e mais importante teatro da cidade; ao longo do tempo sua construção sofreu várias modificações e restaurações, o estilo arquitetônico é Neoclássico. A Casa da Ribeira, também está localizada no bairro histórico e cultural da Ribeira; destaca-se pela qualidade de suas instalações e pela arquitetura que apresenta traços rústicos e sofisticados, numa mescla de estilos.

Para a consecução desta pesquisa, observa-se que quanto aos procedimentos, é suportada por uma abordagem de pesquisa qualitativa, porque apresentou caráter analítico e buscou compreender nas falas dos sujeitos (steakholders) quais sejam: Secretaria Municipal de Turismo - SETUR (na pessoa do Secretário, o Sr. Fernando Bezerril) agentes de viagem, proprietários e funcionários de restaurantes, gestores e colaboradores do segmento da hotelaria, bem como os turistas, como estes estão relacionados no contexto do tratamento do produto turístico cultural.

Os instrumentos de pesquisa usados para a coleta de dados basearam-se em formulários com perguntas abertas e fechadas aplicados aos turistas, na praia de Ponta Negra, cuja aplicação acontecera em dois finais de semana do mês de dezembro de 2008 e em entrevistas realizadas na Secretaria Municipal de Turismo e junto aos agentes de viagem, proprietários e funcionários de restaurantes, gestores e colaboradores do segmento da hotelaria potiguar.

\section{REFERENCIAL TEÓRICO}

\section{A evolução e as tendências da atividade turística}

O turismo é uma prática muito antiga, pode-se considerar que sua existência esteja diretamente relacionada à prática do Grand Tour. ${ }^{2}$ Contudo, é incoerente e incerto afirmar

\footnotetext{
${ }^{2}$ Grand Tour : com objetivo de aprimorar a educação que era oferecida aos filhos das altas camadas sociais da Europa, os nobres financiavam viagens de estudo aos filhos, acompanhados de seus tutores.
} 
uma data ou um acontecimento exato que defina o início da prática dessa atividade. Segundo Lickorish e Jenkins (2000) a primeira viagem organizada foi promovida em 1841 por Tomas Cook, figura de destaque na história da atividade turística, por ser considerado o primeiro operador de viagens que se tem notícia. Cook montou pacotes de viagens em que negociava as passagens, a hospedagem e as atrações que os viajantes estariam visitando.

O turismo é um fenômeno social e seu conceito abrange uma grande gama de teorias, cada uma delas embasadas a partir de um segmento ou aspecto dessa atividade. De acordo com a OMT (Organização Mundial do Turismo) é possível conceituar à atividade citada da seguinte forma:

O turismo inclui tanto o deslocamento e as atividades realizadas pelas pessoas durante suas viagens e estadas bem como as relações que surgem entre eles em lugares distintos de seu ambiente habitual, por um período de tempo consecutivo inferior a um ano e mínimo de 24 horas (pernoite no destino), principalmente com fins de lazer, negócios e outros (OMT apud BALANZÁ e NADAL, 2003, p. $5)$.

Assim, pode-se considerar que um dos elementos fundamentais para se classificar ou conceituar o turismo é tomar por base o tempo de permanência do turista no destino e as atividades por ele realizadas.

É necessário frisar que o turismo não se resume ao simples ato de viajar, e não deve ser classificado, exclusivamente, pelo tempo de estadia do turista em um determinado local ou apenas pela movimentação na economia que este setor promove. Ele não pode ser visto tão somente como uma atividade econômica, mas principalmente como agente de desenvolvimento e inclusão, que tem como característica fundamental as relações de troca cultural entre os diferentes, aproximando realidades díspares.

É importante ter em mente a dimensão, o potencial e o crescimento da atividade turística; porque, assim como a tecnologia e a ciência, o turismo evolui em grande velocidade. Se anteriormente as pessoas viajavam apenas por necessidade de sobrevivência ou com o foco exclusivo no lazer, atualmente, as motivações são as mais variadas e abrangentes possíveis. E para que as expectativas geradas a partir da motivação dos turistas possam ser atendidas e, principalmente superadas, é necessário diferenciar as formas de se praticar turismo.

Dentre os diversos tipos de turismo pode-se destacar o turismo cultural, que se apresenta como uma importante ferramenta na descentralização e de diversificação da oferta turística em todo o Brasil. Entende-se como turismo cultural as viagens motivadas pela vontade do turista em conhecer e interagir com a cultura do local visitado; não apenas no que tange aos aspectos contemplativos, mas principalmente através da imersão do turista em uma realidade completamente diferente da sua. A cada dia o turista busca contato com o novo, com o exótico, com aquilo que foge do cotidiano das grandes metrópoles.

Por isso o turismo cultural vem se tornando uma tendência no setor turístico brasileiro, haja vista as cidades de Ouro Preto - MG ou Petrópolis - RJ, que vem desenvolvendo roteiros próprios em que o ponto central é a visita aos atrativos histórico-culturais e contrariamente ao que ocorre nos destinos de sol e mar, os destinos histórico culturais sofrem bem menos com a sazonalidade, já que pode ser praticada em qualquer época do ano. Os aspectos positivos dessa modalidade para o destino receptor, é que através dela, 
resgata-se a cultura, as características sociais e a riqueza histórica dos destinos, fortalecendo a identidade cultural local e proporcionando assim, condições de oferecer ao turista muito mais que as belas praias e paisagens do litoral nordestino brasileiro.

\section{TURISMO CULTURAL}

A modalidade do turismo cultural pode ser considerada, portanto, uma prática emergente. Para analisar esse processo, se faz necessário buscar compreender o que é cultura, e qual a sua força e importância dentro da atividade turística, independente da modalidade praticada, pois todas as modalidades turísticas existentes promovem a interação e a troca de experiências entre o visitante e a localidade visitada.

Cultura é a "soma total de idéias, reações emocionais condicionadas a padrões de comportamento habitual que seus membros adquiriram por meio da instrução ou imitação e de que todos, em maior ou menor grau, participam" (Linton apud Marconi, Pressoto, 2002, p. 43). Assim, é claro perceber que todos influenciam nos aspectos culturais de um dado lugar; a cultura não é algo que foi criado e imposto; ela vai sendo construída e adquirida por aqueles que convivem e habitam em um determinado ambiente, até mesmo por aqueles que visitam ou passam apenas um período no local.

A primeira modalidade de turismo praticada, em meados do século XVI foi o turismo cultural, através do Grand Tour. Os turistas participantes destas viagens tinham como foco a contemplação de monumentos e de tudo mais que se relacionava com a arte da Grécia Antiga e Roma (BRASIL, 2006).

Assim, ao longo da história o turismo, focado na cultura, vem se desenvolvendo, adquirindo novas características, oferecendo novas motivações para os viajantes e se tornando cada vez mais um segmento acessível às diversas classes sociais. $\mathrm{O}$ turismo cultural tem como foco principal a valorização e a disseminação da cultura local a partir do patrimônio, história e cultura do destino. É possível caracterizar patrimônio histórico e cultural como o conjunto de bens materiais e imateriais encontrados no destino turístico, que vai dos sítios arqueológicos às galerias de artes visuais, teatros, festas e celebrações locais. Nesse contexto convém supor que a cultura e o turismo possuem uma relação estreita e, que o turismo cultural pode diversificar a oferta dos produtos sol e mar, realidade abrangente em todo o litoral nordestino do Brasil.

\section{DIVERSIFICAÇÃO DA OFERTA TURÍSTICA EM NATAL, A PARTIR DO TURISMO CULTURAL}

A beleza natural do Brasil é composta por praias exóticas, matas exuberantes e clima agradável, que vai do frio na região Sul, ao calor em maior destaque na região Nordeste.

Assim, é inegável a importância dos recursos naturais brasileiros para a prática da atividade turística no país, porém, é um equívoco a valorização e utilização exclusiva destes recursos no desenvolvimento da atividade turística nacional. Os recursos naturais de determinado local não são fatores exclusivos na decisão do turista quanto ao destino escolhido para visitação. Entre as diversas motivações que levam o turista a eleger determinada localidade, pode-se destacar como fator significante a cultura local em suas diversas manifestações e formas. E se estas motivações não forem consideradas, durante o 
planejamento que objetiva o crescimento e o desenvolvimento da atividade pelos envolvidos de forma direta ou indireta, a atividade não caminhará para uma evolução equilibrada e sustentável.

Segundo dados da Empresa Potiguar de Promoção Turística - EMPROTUR (2009) o maior responsável pela queda do fluxo do turismo internacional na cidade do Natal é a falta de diversificação da oferta, além da crise financeira mundial, na qual Natal tornou-se um destino caro se comparado a alguns concorrentes diretos: Ilhas Baleares, Caribe, Porto Rico que também apresentam como principal produto o turismo de sol e mar, exploram o patrimônio histórico cultural de forma a agregar valor à experiência turística, apresentando a cada nova temporada, ao menos um produto turístico incorporado ao que já se possui, e por fim, mas não menos importante o quesito custo. A oferta dos atrativos e produtos turísticos do destino Natal não justifica o significativo aumento dos preços face aos valores praticados pela concorrência. Dessa forma, é importante que colaboradores, empresários, agentes de serviços, público ou privado, do turismo; estejam atentos aos diversos segmentos e tendências da atividade turística.

Baseado nas informações a respeito do turismo cultural e das motivações da viagem dos turistas, já elencadas, pode-se afirmar que: em Natal, a diversificação da oferta turística é uma necessidade real e urgente, pois, a cidade, capital do Rio Grande do Norte está entre os 65 destinos indutores do turismo no Brasil, reconhecida nacional e internacionalmente, apenas pela riqueza de litoral e generosidade do sol (presente no local quase que o ano inteiro).

Porém, a riqueza histórica e cultural de Natal é concomitante à oferta dos recursos naturais; tornando real, possível e viável a diversificação da oferta do turismo sol e mar e a diminuição da sazonalidade com a prática do turismo cultural como mostra Barbosa (2004, p. 21):

\footnotetext{
A cidade do Natal, ao apresentar como forte característica o turismo de sol e mar, sem muita preocupação com as tradições culturais, conduz a uma excelente oportunidade para o investimento no turismo cultural, o que pode vir a atrair turistas de outros segmentos, ampliando, assim, as opções de permanência do turista que visita a cidade, já que somente as alternativas de sol e mar induzem a uma estada relativamente curta e com poucas opções de lazer nos turnos vespertino e noturno (BARBOSA 2004, p. 21).
}

Assim, é evidente a importância dos produtos sol e mar em Natal, porém é igualmente evidenciado que, a utilização destes dois recursos, somente, não fará do turismo local uma atividade diferenciada e não garantirá ao turista, opções de diversão, entretenimento e lazer nos momentos em que o Sol não esteja presente, ou não for aprazível o banho de mar. E ainda, não atenderá as perspectivas de uma grande parcela dos turistas que, dentre outros tantos motivos, viajam para viver a experiência das manifestações culturais através do contato direto com os costumes do destino.

As atividades culturais permitem um maior planejamento da atividade turística, independente do favorecimento da estação do ano, daí ser considerada uma modalidade que sofre menos reflexos da sazonalidade. Inclusive como instrumento de apoio na época da baixa estação, explorar a oferta cultural pode significar contribuir para a recuperação dos atrativos naturais que foram consumidos na alta temporada. Ou seja: enquanto os recursos histórico-culturais são explorados, os naturais podem passar por uma fase de 
recuperação, limpeza e descanso. É necessário diversificar a oferta turística em Natal, para que, assim, a concentração dos turistas na cidade não seja resumida apenas ao período de alta estação. Contudo, a criação de novos produtos e o aprimoramento dos recursos existentes, é fator decisivo para isso.

\section{VIABILIDADE DA TRANSFORMAÇÃO DO TEATRO EM PRODUTO TURÍSTICO}

O teatro é a expressão artística considerada internacionalmente como sexta arte. Sua principal característica é o ato da apresentação e representação; para que ele seja completo são necessários três elementos fundamentais: o ator, o texto e o público. A arte teatral, para sua concretização, pode ser aliada a outras formas de manifestações artísticas, tais como a dança e a música. Essa arte desempenha junto ao turismo cultural, a função de ferramenta eficaz na reprodução e propagação da cultura de qualquer localidade, pois através dela é possível contar a história de um povo e reafirmar sua identidade cultural por meio de um entretenimento diferenciado e criativo. O Ministério de Turismo destaca os mais importantes atrativos do turismo cultural da seguinte forma:

\footnotetext{
Um dos principais passos para a estruturação desse tipo de turismo é identificar e avaliar se na região existem atrativos culturais, significativos, efetivos ou potenciais, que possam motivar o deslocamento do turista especialmente para conhecê-los (BRASIL, 2006b, p. 15).
}

Natal se insere nesse contexto por apresentar diversos atrativos ligados a sua história e cultura; que, potencializados, poderiam atrair a atenção de turistas que além dos aspectos naturais, vivenciarão a experiência de voltar seu olhar para os aspectos histórico-culturais do destino visitado. O turismo da cidade do Natal demanda a diversificação e descentralização da oferta turística; e as manifestações e usos populares são fortes ferramentas para isso.

Existe no Rio Grande do Norte, na cidade de Mossoró, uma experiência de turismo cultural bastante interessante: o produto Chuva de Bala no País de Mossoró, espetáculo teatral que acontece todos os anos no mês de junho. Mossoró, cidade localizada no Pólo Turístico Costa Branca, apresentava grande desvantagem em relação a outras cidades do Rio Grande do Norte pela ausência de atrativos naturais (a mesma não é banhada pelo mar). No entanto, através de uma iniciativa popular, com apoio do poder público e da iniciativa privada, o espetáculo Chuva de Bala no País de Mossoró tornou-se referência cultural do povo mossoroense, que atrai grandes fluxos de turistas a nível local, regional e nacional todos os anos.

Assim, o resgate dos teatros em Natal como atrativos turísticos histórico-culturais torna possível agregar valor à oferta turística atual e complementá-la, e com o tempo e os devidos ajustes, tanto os teatros como patrimônio arquitetônico, quanto às peças teatrais, enquanto patrimônio imaterial poderão vir a tornar-se produtos turísticos consolidados, capazes de atrair a atenção dos turistas principalmente nas ocasiões de alta sazonalidade que sofrem os destinos de sol e mar, inclusive aumentando o tempo médio de permanência do turista no destino. 


\section{LEI DJALMA ( N $^{\circ}$ 5323/2001) MARANHÃO COMO INCENTIVO À CULTURA EM NATAL}

A lei Djalma Maranhão aparece como um importante meio de incentivo às manifestações artísticas da cidade. Ela é legislação homologada pela prefeitura do Natal, foi sancionada em 2001 e objetiva estimular o desenvolvimento e a geração de produtos artísticos, tais como: teatro, música, dança, literatura, culinária, museus, centros culturais, bibliotecas, folclore, artesanato, artes plásticas, cinema, fotografia, acervo e patrimônio históricocultural, dentre outros.

Motivados por incentivos fiscais as pessoas sejam elas físicas ou jurídicas, investem em projetos ligados à arte dentro da cidade e garantem benefícios para o recolhimento de seus impostos. Os projetos beneficiados por essa lei devem destinar à Fundação Cultural Capitania das Artes, $10 \%$ (dez por cento) do rendimento dos resultados obtidos. A criação de leis como essa é importante para a cidade e consequentemente para o turismo local, pois, quanto maiores forem os incentivos a projetos que desenvolvam e propaguem os aspectos culturais da cidade, maiores serão as possibilidades de crescimento do turismo cultural nos destinos.

Sob a análise da Lei Djalma Maranhão, observa-se que Natal pode estar á frente de vários destinos de sol e mar, uma vez que há uma lei que ofereça suporte para que os recursos histórico-culturais em suas múltiplas manifestações possam acontecer, o que é mais difícil em cidades que não disponham desse suporte legal. Entretanto, é necessário destacar que apenas a existência da lei não garante a boa utilização dela, é necessário ter, por parte de quem beneficia e de quem é beneficiado a permanência concreta de um foco do que esta lei permite e idealiza. Do contrário, os resultados não serão positivos e agirão de forma contrária ao proposto.

É condição sine qua non que os stakeholders, dentro do setor turismo, tenham consciência da importância da lei Djalma Maranhão, e invistam, apóiem e propaguem-na para que ela possa beneficiar diretamente, o turismo da cidade do Natal e viabilizar o desenvolvimento de novas modalidades de turismo.

\section{A IMPORTÂNCIA DOS STAKEHOLDERS À LUZ DA TEORIA DAS REDES NA PROMOÇÃO DE NOVOS PRODUTOS TURÍSTICOS}

O termo stakeholders é utilizado dentro da administração e foi criado para definir e diferenciar de forma mais clara os acionistas de um sistema organizacional dos outros membros envolvidos, que também se apresentam como base forte dentro da organização. Pode-se conceituar os stakeholders como o conjunto de todos os atores envolvidos em uma organização, incluem qualquer grupo ou indivíduo que possa afetar ou é afetado pelos objetivos organizacionais (CAMPOS, 2008).

Transpondo a discussão dos stakeholders para o universo das redes, como elemento independente que sistematicamente uniriam esforços para a consecução de resultados coletivos e satisfatórios. Conforme observa Nohria (1992) a rede social pode ser caracterizada como um conjunto de pessoas e organizações unidas por um conjunto de relacionamentos sociais. Com isso pode-se tentar compreender como estão relacionados os agentes do turismo de forma a proceder a análise que culmine com a possibilidade ou não de tratar os produtos culturais como produto de marketing turístico. 
Todavia, não é possível restringir essa linha de denominação como definição exclusiva. É válido dizer que o conceito desse termo (stakeholder) não pode ser restrito a um único significado, pois, ao longo da história ele vem se desenvolvendo e agregando novas teorias, juntamente com conceitos mais aprofundados e abrangentes. Esse termo também pode ser discutido dentro do contexto turístico, que abrange uma série de envolvidos por meio direto ou indireto na amplitude da atividade.

Uma questão importante na análise de redes é a identificação de instituições (pessoas ou estruturas organizacionais) no recorte da análise, e o estudo de sua organização em grupos, como também a possibilidade de que sejam elos importantes na troca de determinado tipo de informações (ACIOLE, 2007).

Stakeholders ainda podem ser caracterizados como todos os atores envolvidos nos ambientes externos e internos da organização ou atividade, é viável destacar e denominar os de maior importância dentro do turismo, a saber: prefeitura, pela Secretaria Municipal de Turismo, empresários, colaboradores do segmento de hotelaria e restaurantes, agentes de viagens e os turistas. Além desses atores, é a população local, na qualidade de artistas e artesãos que irá fomentar as manifestações culturais e usos populares.

Portanto, o papel dos atores que compõem a rede é identificar, promover e incentivar novos produtos do turismo na cidade, enquanto o papel da população local é afirmar sua identidade cultural a fim de transformá-la em elemento de interesse turístico. A fim de ilustrar a discussão, estão apresentadas no Quadro 01 algumas das principais manifestações culturais da cidade do Natal:

\section{Quadro 01 - Manifestações Culturais da Cidade do Natal}

\begin{tabular}{|c|}
\hline Auto da Paixão \\
Auto de Natal \\
Brasil mostra Brasil \\
Carnatal \\
\hline Festa de Nossa Sra. Da Apresentação \\
\hline Festival da Canção Potiguar \\
\hline Festival de Quadrilhas Juninas \\
FIARTE \\
\hline Natal em Natal
\end{tabular}

Fonte: PDITS - Plano do Desenvolvimento Integrado do Turismo Sustentável, 2010

Considerar as declarações, sugestões, conceitos e manifestações dos stakeholders, em relação ao turismo local é fundamental, uma vez que eles são peças chaves para o planejamento de metas que buscam a descentralização da oferta turística de Natal, ou seja suas expressões e ações, quando convergentes possibilitam afirmar que há uma transformação na sociedade. Dessa forma, será possível promover uma nova imagem da cidade para os destinos emissores de turistas, sejam eles nacionais ou internacionais, e assim, garantir a presença dos turistas ao longo do ano inteiro, sendo eles motivados a permanecerem no local por outros atrativos turísticos que não estejam ligados, somente, ao segmento sol e mar. 


\section{DISCUSSÃO E ANÁLISE DOS RESULTADOS}

\section{O cenário atual do turismo cultural e das manifestações artísticas em Natal, com a palavra, os stakeholders}

Para compreensão da situação atual do turismo cultural em Natal e para entender se é possível e rentável a promoção das manifestações artísticas locais como atrativos complementares na atividade turística optou-se pela aplicação de formulários compostos por perguntas abertas e fechadas direcionados aos stakeholders: turistas; bem como a realização de entrevistas a pessoas envolvidas na Secretaria de Turismo da Cidade do Natal (SETUR).

A SETUR, dentre diversas responsabilidades referentes à atividade turística local assume o papel de importante órgão planejador da atividade turística, e a EMPROTUR ${ }^{3}$ é o órgão divulgador e promotor dos produtos e da oferta turística da capital do Rio Grande do Norte. Portanto, para entender o presente cenário do turismo cultural local é de fundamental importância que se conheça a situação atual, as propostas e as metas da secretaria responsável pelo turismo.

Sendo assim, na percepção do Secretário de Turismo, Sr. Fernando Bezerril e de outros técnicos que estão envolvidos nas ações do turismo dentro da SETUR, podendo assim, ter uma noção de como se encontra a atividade turística da cidade e, a partir daí, denotar a viabilidade de se promover novos produtos turísticos e, consequentemente, encontrar caminhos que possibilitem a descentralização da oferta turística em Natal.

Identificou-se que atualmente Natal continua sendo divulgada como uma cidade de abundante sol e mar. Mas, juntamente a essa imagem embora que de forma ainda bastante embrionária, já foi iniciada a promoção dos aspectos culturais da cidade. Através dos folders, entregues pelos sujeitos de pesquisa que divulgam a cidade no âmbito nacional e internacional, já é possível encontrar fotos que promovem os aspectos culturais da cidade; tais como: imagens do teatro Alberto Maranhão, de encontros com escritores natalenses, do espetáculo teatral Auto do Natal; de diversas outras manifestações artísticas e do Corredor Cultural $^{4}$.

Quando questionado sobre a centralização da oferta turística em Natal o secretário municipal afirma que "em Natal já está sendo trabalhado o turismo cultural, um exemplo disso é o projeto de se concretizar a visitação dos turistas ao Corredor Cultural" o que, segundo o investigado, vem sendo planejado e estruturado, para que possa, de forma concreta, diversificar a oferta turística de Natal.

Outro aspecto bastante ressaltado pelo Sr. Bezerril foi o grande empenho da secretaria municipal de turismo, através da EMPROTUR em divulgar o "Natal em Natal", que consiste numa série de eventos no período compreendido entre dezembro e janeiro, e possui como destaque principal os espetáculos Auto do Natal, Presente de Natal e o evento do Carnatal; "foram investidos quase cinco milhões de reais no 'Natal em Natal' afirma o entrevistado.

\footnotetext{
${ }^{3}$ EMPROTUR - Empresa Potiguar de Promoção Turística.

${ }^{4}$ Corredor que compreende os bairros de Cidade Alta e Ribeira, onde é possível encontrar construções e monumentos históricos, de relevante importância, na história e cultura da cidade de Natal.
} 
Porém, quando questionado a respeito de projetos e metas definidas, no que se refere ao turismo cultural, para os próximos anos, o secretário não apresentou informações precisas e encaminhou o pesquisador para dialogar com o diretor de projetos, Marcelo Alvin. Segundo ele, o Sr. Alvin, seria o técnico de dentro da secretaria, mais inteirada às especificações de tudo que se refere ao turismo cultural em Natal. Já se percebe a fragilidade da possível rede a qual ainda está em formação (informal), pois um dos principais atores envolvidos se quer tem conhecimento do tema, aqui investigado.

No diálogo com o Sr. Marcelo Alvin, foi possível conhecer e entender melhor o Corredor Cultural; que está localizado na área central da cidade, onde nasceu Natal, ele compreende diversos monumentos e prédios históricos e de grande valor cultural, dentre eles o teatro Alberto Maranhão. Ao ser indagado se existem projetos concretos que definam o acontecimento de manifestações artísticas no momento em que os turistas visitariam o corredor Cultural, para que através do entretenimento fosse contada e divulgada, de forma atrativa, a cultura e a história da cidade do Natal, o diretor de projetos respondeu: "percebemos a necessidade dessas manifestações, como peças teatrais ou shows musicais e há uma preocupação nesse sentido, mas não temos projetos concretos para isso". É perceptível que dessa forma, a visitação dos turistas ao Corredor Cultural, se resumiria em uma passagem rápida por monumentos e prédios; sem proporcionar aos turistas uma experiência mais profunda com a cultura local, ação essa que poderia ser promovida pelas manifestações artísticas que representem à cultura do Rio Grande do Norte.

Contudo, pode-se afirmar que Natal apresenta recursos históricos, bem como projetos que objetivem a valorização do patrimônio material, no que se refere à cultura, e para divulgação da cidade a partir desses aspectos. Mas, não há um empenho mais forte e focado, por parte da SETUR, para o desenvolvimento desses recursos como produtos turísticos ou como meio de diversificar a oferta turística local, salvo o apoio que os stakeholders de turismo e a prefeitura oferecem aos espetáculos Auto do Natal e Presente de Natal. Ambos já se utilizam da arte teatral, da música e da dança para representar a história do nascimento de Cristo de forma diferenciada, de forma que os aspectos culturais local sejam propagados. Estes espetáculos também oferecem uma opção de entretenimento bastante diferenciado para a comunidade local e para o turista que se encontra em Natal, assim como o projeto do Corredor Cultural.

Com isso, percebe-se que os agentes interlocutores do turismo, ainda não se encontram suportados pela mesma lógica de uma nova configuração do tratamento da capital como produto cultural. As relações na rede, além de não serem visivelmente detectadas, pois não há uma emergente interação, não existem ainda construções coletivas comuns no que se venha a propor ao trade turístico.

Visto a importância de estudar e entender as práticas da SETUR e da EMPROTUR é igualmente essencial saber como os demais stakeholders (agentes de viagens, empresários e colaboradores de hotelaria e restaurantes) se posicionam dentro da atividade turística e quais são as suas contribuições efetivas para melhoria da atividade e descentralização da oferta no destino Natal.

Através de entrevistas junto aos agentes de viagem, empresários de agências, proprietários e funcionários de restaurantes, gestores e colaboradores da hotelaria; foi possível perceber que tais stakeholders têm consciência de seu papel de agentes influentes sobre os turistas. 
Ao serem questionados sobre qual o nível de relevância que eles possuíam dentro do turismo local grande parte deles respondeu que são extremamente importantes e que os turistas sempre recorrem a eles para saber o que há de interessante e quais os programas existentes dentro da cidade. Ao serem questionados a respeito do que eles sentem falta no turismo em Natal, a resposta que prevaleceu foi: outras formas de entretenimento que se possa indicar ao turista que não seja a praia e o mar.

Quando questionados sobre o que era feito para divulgar o turismo cultural e as manifestações artísticas da cidade, a resposta predominante dos sujeitos foi que "não tinham o que fazer, pois desconheciam a existência desses em Natal, se existissem eles divulgariam". Em se tratando os atores da rede como constituintes de atividades fins diferentes, que objetivamente orientam a ação de melhora do turismo, percebe-se certa inércia de alguns atores em face do comportamento caracterizado pela não pró atividade dos demais, que prioritariamente deveriam se engajar eficazmente, como é caso dos atores públicos.

Propõe-se então que esses stakeholders possam se unir e trabalhar para que haja, em lugares bastantes frequentados pelos turistas, como a praia de Ponta Negra, manifestações artísticas do tipo: festivais de teatro, shows musicais, apresentações folclóricas, espetáculos de dança, encontros de escritores e poetas locais, dentre diversos outros, agregando assim entretenimento interessante e diversificado no local e possibilitando então uma permanência maior do turista nos pontos mais visitados da cidade, "já que somente as alternativas de sol e mar induzem a uma estada relativamente curta e com poucas opções de lazer nos turnos vespertino e noturno" (BARBOSA, 2004, p. 21). Dessa forma os restaurantes, as feiras de artesanato e outros estabelecimentos, poderiam contar com uma presença de clientes durante todo o dia e não somente no período matutino, movimentando melhor a economia local.

Para tanto, é importante evidenciar que para a propagação de novos, ou já existentes, produtos turísticos ligados ao segmento cultural, dentro da cidade do Natal, é fundamental que haja uma conscientização, seguida de uma forte adesão de comprometimento e conhecimento dos aspectos e produtos do turismo cultural por parte desses stakeholders.

Os turistas também são stakeholders, tão importantes quanto os já citados, e perceber o quê eles buscam, vêem e pensam a respeito do turismo em Natal é extremamente relevante, em especial dentro do contexto atrativo cultural. Por isso, foram aplicados formulários, na praia de Ponta Negra, com os praticantes da atividade turística e, mediante análise dos dados coletados, percebeu-se que os visitantes, ao escolherem Natal como destino turístico, foram atraídos à cidade pelos recursos naturais que ela oferece. Todos eles, ao pensarem na capital do Rio Grande do Norte, primordialmente, imaginam um lugar de belas praias e freqüente clima tropical, se quer mencionam os produtos culturais da cidade; consequência da propagação excessiva, quase que exclusiva, do destino tão somente pelos aspectos naturais; resultando na centralização da oferta turística.

Tal resultado é visto através de um desenvolvimento econômico concentrado em pequenos grupos, face os recursos deixados pelos visitantes se destinarem apenas às praias. Quando questionados a respeito dos serviços turísticos e se em Natal há boa receptividade, dos moradores locais, a maioria disse estar satisfeito com ambos e que no geral a cidade possui uma boa infra-estrutura. Porém, o que mais chamou atenção, na coleta de dados com os 
turistas, foi ver a necessidade que eles têm por informações ligadas ao entretenimento e lazer.

Os entrevistados expressaram que a cidade é carente de lugares especializados em dar informações turísticas e que nos locais freqüentados por eles (tais como hotéis, restaurantes, mercados de artesanato, dentre outros) não havia propagação visível de calendários de eventos, cartazes que divulgassem atrações ou manifestações artísticas, teatros, museus ou outros locais que eles pudessem visitar, se entreter e conhecer mais a respeito da cultura local. Todos afirmaram que pedem opiniões à comunidade local e aos colaboradores ligados de forma direta ou indireta ao turismo, também ressaltaram que as informações passadas por eles são decisivas na efetivação de sua programação diária no destino. Ao responder a pergunta sobre qual tipo de manifestação artística mais chamava sua atenção, os turistas entrevistados responderam: teatro, música, dança e folclore e afirmaram que se tivessem conhecimento de eventos desses segmentos disponibilizariam grandes momentos de suas viagens para apreciação dos mesmos.

Mediante o resultado da pesquisa realizada fica iminente a viabilidade da propagação de novos produtos turísticos em Natal, pois os praticantes dessa atividade na cidade anseiam por entretenimento e lazer diversificado, bem como por um contato mais direto com a cultura local de forma atrativa e diferenciada, que lhes proporcionem um bom entretenimento e possibilite o aprendizado sobre alguns aspectos culturais da região. É lícito afirmar que o turista, quando ciente das programações artísticas e se norteado por colaboradores do setor do turismo ou até mesmo pela comunidade local, decide por conhecer e prestigiar as manifestações artísticas do destino turístico, principalmente se elas forem compostas pela arte teatral, música ou dança. Porém não há práticas que incentivem e façam com que esses produtos possam ser aproveitados e desenvolvidos dentro dos pontos centrais e focos dos turistas.

Logo, fica evidente a necessidade de que a iniciativa pública promova mais ações, como a Lei Djalma maranhão, que incentivem e propaguem a cultura local. Do contrário o turismo em Natal pode perder a possibilidade de agregar produtos turísticos de grande potencial e consequentemente mercado, para outras cidades que divulgam seus aspectos culturais. É também, de igual importância o papel dos agentes de viagens, colaboradores de hotéis, restaurantes e de todos os setores que direta ou indiretamente trabalham com a atividade turística. Eles são essenciais na divulgação de novos, ou dos já existentes, produtos turísticos, pois, o fato de possuírem contato direto com o turista, influenciam de forma concreta as escolhas de lazer e entretenimento do visitante, durante todo o período de estadia deles no local.

Vale ressaltar que a promoção, a melhoria e a divulgação de novos produtos turísticos, principalmente os de aspecto cultural, precisam chamar a atenção dos envolvidos, que são os turistas. Por isso é necessário ouvi-los e perceber a forma mais eficiente de se conseguir disseminar a cultura do destino, promovendo uma junção entre sua imagem e a diversidade cultural. Com isso todos os produtos que valorizem a cultura potiguar, como o corredor Cultural, as manifestações artísticas e todo o patrimônio histórico cultural material ou imaterial serão alternativas reais e concretas de negócios, bem como, ferramentas eficientes na descentralização da oferta turística em Natal. 


\section{CONSIDERAÇÕES FINAIS}

Atualmente, apesar do grande potencial que Natal possui para o desenvolvimento do turismo cultural, os envolvidos na atividade turística da cidade, stakeholders - empresários, Secretaria Municipal de Turismo, agentes de viagens, profissionais do segmento da hotelaria ou de restaurantes, dentre vários outros - percebem a necessidade de se obter novos produtos dentro da cidade, mas ainda direcionam suas atenções, de forma mais intensa, para o segmento do turismo de sol e mar. Com isso, acabam não explorando eficientemente novas formas de se praticar a atividade turística, como pelo turismo cultural.

Não são investidos esforços para propagação da história e cultura local através de formas eficientes e significativas; tais como pelas manifestações artísticas, sejam elas, teatro, música dança ou folclore. $\mathrm{Na}$ verdade não se pode falar ainda que exista uma rede de relacionamentos formatada para objetivos comuns. São laços quase inexistentes que precisam ser externalizados.

O teatro, por exemplo, quanto manifestação artística ou estrutura física, respectivamente, é um objeto real do patrimônio imaterial e material da cidade do Natal. E apesar da não utilização intensa deste recurso artístico, ou falta da propagação dele como oferta turística dentro do destino; é viável afirmar, ainda assim, que o mesmo caracteriza-se e se constitui como ferramenta para todos os envolvidos no turismo da cidade, que procuram um meio eficiente e real no objetivo de descentralizar a oferta turística local e na tentativa de desvincular a imagem da capital do Rio Grande do Norte das palavras exclusivas: sol e mar.

Por isso é possível reafirmar que é fundamental haver, por parte da iniciativa pública e privada (atores), uma atenção mais específica para o patrimônio cultural material e imaterial da cidade, tais como: os pequenos e grandes espetáculos (Auto do Natal, Presente de Natal, Paixão de Cristo, shows de folclore); o Corredor Cultural, que dentre vários monumentos e prédios históricos, abriga o teatro Alberto Maranhão. Pois através da potencialização deles como atrativo turístico é possível promover uma maior movimentação econômica da atividade turística em Natal, bem como viabilizar a descentralização dessa oferta no destino. Uma das saídas será o ator público passar a criar mecanismos de solidificação/sedimentação da rede, saindo da estrutura da atitude e conhecimento da necessidade desta descentralização e efetivar ações coordenadas para isso. È uma junção de esforços e olhares que carece de ser implementado conjuntamente.

\section{REFERÊNCIAS}

1. ACIOLE. S. Redes sociais e teoria social: revendo os fundamentos do conceito.Inf. Londrina, v. 12 , n. esp., 2007.

2. BALANZÁ, Izabel Milio; NADAL, Mônica Cabo. Marketing e comercialização de produtos turísticos. São Paulo: Thompson, 2003. 222 p.

3. BARBOSA, Andréia Dantas et al. Turismo: cultura lazer e possibilidades de intervenções. Natal: Banco do Nordeste, 2004. 141 p.

4. BRASIL. Ministério do Turismo. Cultura e Turismo: Caminhos do Futuro. Brasília, 2007. 
5. CAMPOS, Taiane Las Casas . Administração de stakeholders: uma questão ética ou estratégica. Artigo científico. Disponível em: 〈http://iceg.pucminas.br/apimec〉. Acesso em: 01 set. 2008.

6. COOPER, Chris. FLETCHER, John. WANHIL, Stephen. GILBERT, David. DATAR, M.T., BHARGAVA, D.S. Effects of environmental factors on nitrification during aerobic digestion of activated sludge. Journal of the Institution of Engineering (India), Part EN: Environmental Engineering Division, v.68, n.2, p.2935, Feb. 1988.

7. FADINI, P.S. Quantificação de carbono dissolvido em sistemas aquáticos, através da análise por injeção em fluxo. Campinas, 1995. Dissertação de mestrado-Faculdade de Engenharia Civil-Universidade Estadual de Campinas, 1995.

8. Ministério do Turismo. Turismo Cultural: Orientações Básicas. Brasília, 2006.

9. LICKORISH, L. J.; JENKINS, C. L. Introdução ao turismo. Rio de Janeiro: Campus, 2000.

10. NOHRIA, N. Is a network perspective a useful way of studying organizations? In: NOHRIA, N. \& ECCLES, R. G. (Ed.). Networks and organizations: structure, form, and action. Boston, Massachusetts: Harvard Business School Press, 1992, p. 1-22.

11. RUSCHMANN, Doris van de Meene.Turismo e planejamento sustentável: a proteção do meio ambiente. Campinas, SP: Papirus, 1997

12. SHEPERD, Rebecca; trad. Roberto Cataldo Costa. Turismo, princípios e práticas. $2^{a}$ edição, Porto Alegre: Bookman, 2001. 